\title{
Protocol for a parallel economic evaluation of a trial comparing two surgical strategies in severe complicated intra-abdominal sepsis: the COOL-cost study
}

\author{
Joshua S. Ng-Kamstra ${ }^{1 *}$ (D), Elissa Rennert-May², Jessica McKee ${ }^{3}$, Skyla Lundgren, Braden Manns 5,6
} and Andrew W. Kirkpatrick ${ }^{1,3,7}$

\begin{abstract}
Background: The risk of death in severe complicated intra-abdominal sepsis (SCIAS) remains high despite decades of surgical and antimicrobial research. New management strategies are required to improve outcomes. The Closed Or Open after Laparotomy $(\mathrm{COOL})$ trial investigates an open-abdomen $(\mathrm{OA})$ approach with active negative pressure peritoneal therapy. This therapy is hypothesized to better manage peritoneal bacterial contamination, drain inflammatory ascites, and reduce the risk of intra-abdominal hypertension leading to improved survival and decreased complications. The total costs and cost-effectiveness of this therapy (as compared with standard fascial closure) are unknown.

Methods: We propose a parallel cost-utility analysis of this intervention to be conducted alongside the 1-year trial, extrapolating beyond that using decision analysis. Using resource use metrics (e.g., length of stay, re-admissions) from patients at all study sites and microcosting data from patients enrolled in Calgary, Alberta, the mean cost difference between treatment arms will be established from a publicly-funded health care payer perspective. Quality of life will be measured at 6 months and 1 year postoperatively with the Euroqol EQ-5D-5 L and SF-36 surveys. A within-trial analysis will establish cost and utility at 1 year, using a bootstrapping approach to provide confidence intervals around an estimated incremental cost-effectiveness ratio. If neither operative strategy is economically dominant, Markov modeling will be used to extrapolate the cost per quality-adjusted life years gained to 2-, 5-, 10-year, and lifetime horizons. Future costs and benefits will be discounted at 1.5\% per annum. A cost-effectiveness acceptability curve will be generated using Monte Carlo simulation. If all trial outcomes are similar, the primary analysis will default to a cost-minimization approach. Subgroup analysis will be carried out for patients with and without septic shock at presentation, and for patients whose initial APACHE II scores are $>20$ versus $\leq 20$.
\end{abstract}

Discussion: In addition to an estimate of the clinical effectiveness of an OA approach for SCIAS, an understanding of its cost effectiveness will be required prior to its adoption in any resource-constrained environment. We will estimate this key parameter for use by clinicians and policymakers.

Trial Registration: ClinicalTrials.gov, NCT03163095, registered May 22, 2017.

Keywords: Cost-effectiveness analysis, Cost-utility analysis, Quality of life, Randomized controlled trial, Intra-abdominal infections, Sepsis, Laparotomy

\footnotetext{
* Correspondence: josh.ngkamstra@gmail.com

'Department of Critical Care Medicine, University of Calgary, 2500 University

Drive NW, Calgary, Alberta T2N 1 N4, Canada

Full list of author information is available at the end of the article
}

(c) The Author(s). 2020 Open Access This article is distributed under the terms of the Creative Commons Attribution 4.0 International License (http://creativecommons.org/licenses/by/4.0/), which permits unrestricted use, distribution, and reproduction in any medium, provided you give appropriate credit to the original author(s) and the source, provide a link to the Creative Commons license, and indicate if changes were made. The Creative Commons Public Domain Dedication waiver (http://creativecommons.org/publicdomain/zero/1.0/) applies to the data made available in this article, unless otherwise stated. 


\section{Background}

Severe complicated intra-abdominal sepsis (SCIAS) imparts a mortality risk of $30-40 \%$ when individuals present in shock, even with the most advanced care [1-3]. For those who survive, hospitalization is often prolonged and fraught with complications including respiratory failure, renal failure, major cardiac events, wound infections, deep space infections, thromboembolic disease, neurocognitive dysfunction, and prolonged weakness. The high incidence of SCIAS compounds the complexity of care required to treat the disease and its complications, creating a large resource burden for health systems globally. Estimates of the cost of standard care per case in the Netherlands was 86,077 USD in 2010; in Austria, the effective cost "per survivor" was reported as 232,400 USD in 1998 [4, 5].

After initial surgery for SCIAS, in the absence of an absolute indication to leave the abdomen open (for example, bowel left in discontinuity), the fascia is usually closed definitively. With this approach, repeat unplanned laparotomy is commonly required to establish surgical source control [6]. Early closure of the fascia can also lead to abdominal compartment syndrome with impairment of ventilation and renal perfusion.

An alternate strategy of leaving the fascia open ("open abdomen", OA) with active negative pressure peritoneal therapy (ANPPT) is being studied in an international, multisite-randomized controlled trial (Closed Or Open after Laparotomy, COOL); the comparator is standard fascial closure at the initial operation [7]. Investigators hypothesize that ANPPT will allow for ongoing drainage of infected, inflammatory peritoneal fluid, decreasing the systemic propagation of inflammatory mediators $[8,9]$. OA will also facilitate repeat operative washouts; these advantages may improve survival. Both approaches are acceptable options for the management of SCIAS according to World Society of Emergency Surgery guidelines $[10,11]$. Despite varied expert opinion on the merits of the OA approach, an examination of the evidence base reveals persistent equipoise. Even if an OA strategy demonstrates clinical benefit in this trial, costs may be significantly higher in this approach due to increased need for critical care resources, including mechanical ventilation, while the fascia is open [4]. Alternatively, costs may be lower if OA with ANPPT results in rapid resolution of systemic inflammation and a shortened duration of critical illness.

If the OA strategy shows clinical benefit, the resources required to adopt it into practice must be accurately counted; each resource used, including operating room and ICU time, comes with an opportunity cost (i.e., less resources available for other medical treatments). We therefore propose a 1-year prospective cost-utility analysis with robust quality of life valuation to be performed alongside this RCT, using decision analysis to extrapolate beyond 1 year if required. Since the economic implications of this strategy may be large, determining the incremental cost effectiveness ratio of this alternate therapy is important to guide adoption in any resourceconstrained health care environment.

\section{Objectives}

\section{Primary Objective}

The primary objective of this analysis is to estimate the incremental cost-effectiveness ratio of the open abdomen (OA) approach versus fascial closure for SCIAS over the 1-year time horizon of the COOL trial. Resource use data will be requested from all study sites, and total cost estimates will be established based on unit costs derived from microcosting data from Calgary, Alberta.

If all outcomes are similar in the COOL trial, the analysis will instead default to a cost-minimization approach.

\section{Secondary objectives}

Secondarily, we aim to determine mean total cost difference for OA versus primary fascial closure for both the overall cohort and for pre-specified subgroups of patients including:

1. Patients with and without the presence of septic shock at the time of initial surgery

2. APACHE II score $>20$ or $\leq 20$

Further, we will assess quality of life (QOL) after surgical management of SCIAS, identifying determinants of poor quality of life across the study population and quantifying differences in QOL between the two treatment arms.

Finally, if neither operative strategy is dominant (i.e., if greater costs and improved outcomes accrue in one treatment arm), we will conduct a Markov analysis to determine the cost per quality-adjusted life years gained over a lifetime horizon. We will estimate the incremental cost-effectiveness ratio and create a cost-effectiveness acceptability curve using Monte Carlo simulation.

\section{Methods \\ COOL study}

The methodology of the COOL trial has been published elsewhere [7] and is briefly summarized here. To be included in the trial, adult patients will have complicated intra-abdominal infection (purulent, feculent, or enteric contents in the peritoneal cavity at the time of operation) and present with severe disease (either septic shock, World Society of Emergency Surgery Sepsis Severity Score $\geq 8$, or a Calgary Predisposition-InfectionResponse-Organ dysfunction score $\geq 3$ ). Patients will be 
excluded if presenting during pregnancy, if there is a perceived inability to close the abdomen safely without inducing intra-abdominal hypertension, or if there is an absolute indication for "damage control laparotomy," among other exclusion criteria. Patients in the intervention arm of the trial will have the abdomen temporarily closed with an ABTHERA ${ }^{\mathrm{TM}}$ device with planned repeat operation 24-72 $\mathrm{h}$ later. In the control arm, the fascia will be closed in the usual fashion after a closed-suction intraperitoneal drain is placed. Randomization will be performed online after confirming eligibility, with a permuted block randomization strategy to ensure close balance between treatment arms at each site.

\section{Population for COOL-cost}

For the primary cost analysis, the patient population will include all patients randomized to open abdomen (OA) or primary fascial closure in the COOL trial.

Data on resource use will be requested from all participating sites. Microcosting data from Calgary, Alberta, will be used to establish unit costs and develop estimated cost totals.

\section{Identification, measurement, and valuation of resource use}

All costs that may differ between study arms will be considered from a publicly-funded health care payer perspective using a microcosting approach where possible (Table 1). Costs can be divided into those associated with the index hospitalization, follow-up care, any required readmission or delayed inpatient surgical procedure, and day medicine and surgery encounters (Table 2).

A secondary analysis from a societal perspective will be conducted if the data permit. This will include nonmedical and patient-borne costs attributable to the illness and associated care, and the value of lost productivity.

\section{Index hospitalization costs}

First, we will consider the costs of surgery for the alternate strategies. The number of minutes spent in the operating room, care by surgeons and anesthesiologists, and the use of sterilizable surgical tools will be valued and included. The cost of surgical disposables will be included; while temporary abdominal closure devices may be provided free-of-charge by the manufacturer for use in the trial, the market value of these devices will be determined and included.

Postoperatively, the cost of care provided in the postanesthesia care unit, intensive care unit (ICU), and the general ward will be determined and included. The costs of care in ICU are hypothesized to represent a large proportion of the inpatient costs for SCIAS patients and may drive differences in cost between the two treatment
Table 1 Microcosting in the Calgary zone, Alberta Health Services

\section{Microcosting in Alberta}

To determine how costs differ between treatment arms in this analysis, we will use microcosting [12] data from hospitals in the Calgary Zone of Alberta Health Services. Resources used in the management of each patient will be enumerated, valued, and summed to create a highly precise cost-of-care for each individual. Less intensive methodologies using average patient costs for similar groups would be insensitive to the differences in cost between the open abdomen and primary fascial closure arms.

Microcosting is made possible by patient-specific resource use data collected by Alberta Health Services and calculated in accordance with national Management Information Systems guidelines [13]. First, the quantity of physical materials and diagnostics necessary for the care of each patient are tracked. These include medications, blood products, patient-traceable disposables, radiologic investigations, and laboratory tests. The quantity of each is multiplied by the unit cost (estimated annually) to provide a total cost estimate and these are summed. The direct human resources required for care including nursing and support staff are quantified and similarly costed. Physician billing fees are added to this to create a total cost of labor. The indirect costs of the spaces and systems of care (e.g., ICU bed or OR time) are then apportioned to each patient [12]. Costs across these domains are summed to create an estimate of cost for each patient encounter. Outpatient encounter data are also available to estimate the cost of follow-up with specialists, rehabilitation, and outpatient services such as dialysis.

The availability and quality of cost data reporting in Alberta is highly regarded and has previously been used in the assessment of surgical costs [14]. Our primary analysis will combine resource use data from all COOL sites with microcosting data from Calgary to create estimates of cost in each treatment arm.

arms. In the Canadian context, ICU care costs are approximately three times higher than that on a general ward, and so ICU length of stay and costs will be specifically examined in this analysis [15].

The microcosting approach will provide data on the cost of nursing care, diagnostic imaging, percutaneous interventions, laboratory testing (excluding additional testing performed solely for trial purposes), medications including antibiotics, blood products, additional care provided by other health providers including physiotherapy, occupational therapy, and enterostomal therapists, and the costs of disposables required for care in hospital. Furthermore, data will be provided on indirect costs such as patient transport, housekeeping, administration, and building maintenance. These costs will be summed and included in the primary analysis.

\section{Follow-up care costs}

We will include the costs of follow-up with specialist physicians and enterostomal therapists, the management of wound infections, time spent in a rehabilitation facility, and the cost of any ongoing organ support such as hemodialysis for renal failure.

\section{Readmissions}

If readmission to hospital within one year is required for any reason, this will be recorded. Given that the relevance 
Table 2 Microcosting data items required from Calgary, Alberta sites

\begin{tabular}{|c|c|c|c|}
\hline Variable & Description & Data required & Data source \\
\hline \multicolumn{4}{|l|}{ Baseline/Admission data } \\
\hline Patient unique identifier & $\begin{array}{l}\text { Single datum permitting linkage } \\
\text { across multiple databases }\end{array}$ & Unique Lifetime Identifier & COOL trial \\
\hline Hospital at enrolment & $\begin{array}{l}\text { Hospital where initial laparotomy } \\
\text { is performed }\end{array}$ & Site name & COOL trial \\
\hline Patient postal code & $\begin{array}{l}\text { Approximate location of patient's } \\
\text { domicile (necessary for calculating } \\
\text { transportation costs) }\end{array}$ & Postal code & COOL trial \\
\hline Patient age & In years & Age in years & COOL trial \\
\hline Patient sex & Male, female, other & Sex & COOL trial \\
\hline ICD-10 admission diagnosis & Single admission diagnosis & ICD-10 code & $\mathrm{COOL}$ trial \\
\hline Shock at the time of initial OR & $\begin{array}{l}\text { Hypotension requiring pressors for } \\
\text { MAP }>65 \text { or serum lactate } \\
>2 \mathrm{mmol} / \mathrm{L} \text { after resuscitation }\end{array}$ & Yes/No & COOL trial \\
\hline Admission APACHE II score & Severity-of-disease classification score & Score at time of admission & COOL trial \\
\hline \multicolumn{4}{|l|}{ Index hospitalization } \\
\hline \multicolumn{4}{|l|}{ Operating room } \\
\hline Dates of each operating room encounter & During index hospitalization & List of dates & COOL trial \\
\hline $\begin{array}{l}\text { Procedures performed at each operating } \\
\text { room encounter }\end{array}$ & All procedure codes included & List of procedure codes & COOL trial \\
\hline Duration of all operating room encounters & $\begin{array}{l}\text { Documented entry into and exit } \\
\text { from operating room }\end{array}$ & Time in minutes & COOL trial \\
\hline $\begin{array}{l}\text { Anesthetist billings associated with each } \\
\text { operating room encounter }\end{array}$ & Total physician claims & Billings in CAD & $\begin{array}{l}\text { Alberta Medical Association } \\
\text { (AMA) fee schedule }\end{array}$ \\
\hline $\begin{array}{l}\text { Surgeon billings associated with each } \\
\text { operating room encounter }\end{array}$ & Total physician claims & Billings in CAD & AMA fee schedule \\
\hline Operating room drug costs & $\begin{array}{l}\text { List, quantity, and cost of all } \\
\text { medications used during surgery }\end{array}$ & Medications and costs & $\begin{array}{l}\text { Finance oracle microcosting } \\
\text { database (Oracle) }\end{array}$ \\
\hline $\begin{array}{l}\text { List and quantity of disposables used at each } \\
\text { surgical encounter }\end{array}$ & $\begin{array}{l}\text { All non-sterilizable surgical tools } \\
\text { designed for one-time use, as well } \\
\text { as suture materials and dressings }\end{array}$ & List and quantity & Oracle \\
\hline $\begin{array}{l}\text { Surgical instrument sets used at each surgical } \\
\text { encounter }\end{array}$ & $\begin{array}{l}\text { Name of each set used } \\
\text { (e.g., major abdominal) }\end{array}$ & List of instrument sets & Oracle \\
\hline \multicolumn{4}{|l|}{ Postoperative care } \\
\hline Length of stay in ICU and cost & $\begin{array}{l}\text { Stay in a designated critical care } \\
\text { environment }\end{array}$ & Length in days & COOL trial, Oracle \\
\hline Length of stay on general ward and cost & $\begin{array}{l}\text { Length of hospital stay, less the } \\
\text { length of ICU stay }\end{array}$ & Length in days & COOL trial, Oracle \\
\hline Length of stay in post-anesthesia care unit & Stay in a designated PACU & Length in days & Oracle \\
\hline Direct and indirect costs of PACU stay & $\begin{array}{l}\text { Itemized cost of PACU stay including } \\
\text { personnel, disposables, medications, } \\
\text { and overhead costs }\end{array}$ & Costs in CAD & Oracle \\
\hline $\begin{array}{l}\text { Physician billings associated with } \\
\text { hospital stay }\end{array}$ & $\begin{array}{l}\text { Total Alberta Health billings, less } \\
\text { surgeon, and anesthetist operative } \\
\text { billings }\end{array}$ & Billings in CAD & AHS data analytics (DIMR) \\
\hline Postoperative diagnostic imaging costs & $\begin{array}{l}\text { Total of per-study fees, plus the AHS } \\
\text { billings of diagnostic radiologists }\end{array}$ & Costs in CAD & Oracle \\
\hline Postoperative percutaneous procedure costs & $\begin{array}{l}\text { Total of per-procedure fees, plus the } \\
\text { AHS billings of interventional } \\
\text { radiologists }\end{array}$ & Costs in CAD & Oracle \\
\hline Costs of laboratory testing & $\begin{array}{l}\text { Total in-hospital laboratory testing, } \\
\text { less total study-specific laboratory } \\
\text { testing costs }\end{array}$ & Costs in CAD & Oracle \\
\hline
\end{tabular}


Table 2 Microcosting data items required from Calgary, Alberta sites (Continued)

\begin{tabular}{|c|c|c|c|}
\hline Variable & Description & Data required & Data source \\
\hline Inpatient drug costs & Total pharmaceutical costs & Costs in CAD & Oracle \\
\hline Cost of blood products used & $\begin{array}{l}\text { Total cost of in-hospital blood } \\
\text { product use }\end{array}$ & Costs in CAD & Oracle \\
\hline $\begin{array}{l}\text { Cost of nursing and allied health care not } \\
\text { included in per-diem unit cost }\end{array}$ & $\begin{array}{l}\text { Total cost of specialized RN and } \\
\text { other allied health providers }\end{array}$ & Costs in CAD & Oracle \\
\hline $\begin{array}{l}\text { Cost of disposables used in postoperative } \\
\text { patient care }\end{array}$ & Total cost of disposables & Costs in CAD & Oracle \\
\hline \multicolumn{4}{|l|}{ Follow-up care } \\
\hline Number of surgeon visits (to 1 year) & Regardless of reason for visit & Number of visits & DIMR \\
\hline $\begin{array}{l}\text { Number of other specialist physician visits } \\
\text { (to } 1 \text { year) }\end{array}$ & Regardless of reason for visit & Number of visits & DIMR \\
\hline Total outpatient AHS billings & Regardless of reason for services & Billings in CAD & DIMR \\
\hline \multicolumn{4}{|l|}{ Readmissions } \\
\hline $\begin{array}{l}\text { Number and length of each readmission } \\
\text { within } 1 \text { year }\end{array}$ & Regardless of reason for readmission & Number and length in days & DIMR \\
\hline $\begin{array}{l}\text { Total hospital cost, including physician } \\
\text { billings, associated with each readmission }\end{array}$ & Regardless of reason for visit & Costs in CAD & DIMR \\
\hline \multicolumn{4}{|l|}{ Subsequent $O R$ costs } \\
\hline $\begin{array}{l}\text { Dates of each operating room encounter } \\
\text { within } 1 \text { year }\end{array}$ & After index hospitalization & List of dates & COOL trial \\
\hline $\begin{array}{l}\text { Procedures performed at each operating } \\
\text { room encounter }\end{array}$ & All procedure codes included & List of procedure codes & COOL trial \\
\hline Duration of all operating room encounters & $\begin{array}{l}\text { Documented entry into and exit from } \\
\text { operating room }\end{array}$ & Time in minutes & COOL trial \\
\hline $\begin{array}{l}\text { Anesthetist billings associated with each } \\
\text { operating room encounter }\end{array}$ & Total physician claims & Billings in CAD & AMA Fee Schedule \\
\hline $\begin{array}{l}\text { Surgeon billings associated with each } \\
\text { operating room encounter }\end{array}$ & Total physician claims & Billings in CAD & AMA Fee Schedule \\
\hline $\begin{array}{l}\text { List and quantity of disposables used at } \\
\text { each surgical encounter }\end{array}$ & $\begin{array}{l}\text { All non-sterilizable surgical tools } \\
\text { designed for one-time use, as well } \\
\text { as suture materials and dressings }\end{array}$ & List and quantity & Oracle \\
\hline $\begin{array}{l}\text { Surgical instrument sets used at each } \\
\text { surgical encounter }\end{array}$ & $\begin{array}{l}\text { Name of each set used (e.g., major } \\
\text { abdominal) }\end{array}$ & List of instrument sets & Oracle \\
\hline \multicolumn{4}{|l|}{ Ambulatory care costs } \\
\hline $\begin{array}{l}\text { Number, type, and cost of all other } \\
\text { ambulatory encounters (other than family } \\
\text { physician and specialist encounters) }\end{array}$ & $\begin{array}{l}\text { All day medicine and day surgery } \\
\text { encounters (including dialysis) } \\
\text { within one year }\end{array}$ & $\begin{array}{l}\text { Number, type, and costs } \\
\text { in CAD }\end{array}$ & DIMR \\
\hline \multicolumn{4}{|l|}{ Costs to patients and caregivers } \\
\hline $\begin{array}{l}\text { Cost of transportation to and from family } \\
\text { physician and specialist appointments }\end{array}$ & Total estimated costs & $\begin{array}{l}\text { Number of visits, approximate } \\
\text { distance to domicile }\end{array}$ & DIMR \\
\hline \multicolumn{4}{|l|}{ Productivity costs } \\
\hline Number of days absent from work at 1 year & $\begin{array}{l}\text { Self-reported number of days absent } \\
\text { from work }\end{array}$ & Total days & COOL trial \\
\hline \multicolumn{4}{|l|}{ Outcomes } \\
\hline Mortality at 90 days & Primary outcome & Dichotomous variable & COOL trial \\
\hline Mortality at 1 year & Long-term survival & Dichotomous variable & COOL trial \\
\hline Presence of a stoma at initial hospital discharge & Ileostomy or colostomy & Dichotomous variable & COOL trial \\
\hline Presence of a stoma at 90 days and 1 year & Ileostomy or colostomy & Dichotomous variable & COOL trial \\
\hline EQ-5D-5 $L$ and SF-36 at 90 days & Validated quality of life measure & Values at 90 days & COOL trial \\
\hline EQ-5D-5 L and SF-36 at 1 year & Validated quality of life measure & Values at one year & COOL trial \\
\hline
\end{tabular}


of a readmission to the original illness is difficult to determine, the full cost of readmissions will be included in the primary analysis. In a secondary analysis, if it is possible to determine which admissions (or portions thereof) are unrelated to the original illness, these will be excluded.

\section{Surgical procedures after initial discharge}

All surgical procedures within 1 year will be costed and included in the primary analysis. In secondary analysis, only surgeries related to the diagnosis of SCIAS will be included, which might include reversal of an enterostomy, management of an enterocutaneous fistula, or management of an abdominal hernia.

\section{Ambulatory case costing}

We will identify, cost, and include all related outpatient day surgery, day medicine, and emergency room visits occurring after discharge.

\section{Costs to patients and caregivers}

After discharge from hospital, the cost of transportation to and from health care providers will be estimated for each patient by multiplying the number of follow-up visits by the distance traveled to and from the listed home address and using a standard per-kilometer cost value. These costs will be included in secondary analysis from a societal perspective.

\section{Productivity costs}

Absence from paid work after a diagnosis of SCIAS may have significant economic consequences. The number of days absent from paid work after discharge will be tabulated for all individuals less than 65 years of age, and the value of this absence will be calculated using a friction cost methodology and included in secondary analysis [16].

\section{Quality of life}

Quality of life data are being collected in the COOL trial as a secondary outcome, using the Euroqol EQ-5D-5 L and SF-36 surveys at 6 months and 1 year postoperatively. Utility values will be estimated using the EQ-5D$5 \mathrm{~L}$ index score, using the visual analog score as a secondary analysis. We will assess quality of life data across the study population to identify drivers of good or poor quality of life at the 6-month and 1-year mark. We will then quantify differences in quality of life between the $\mathrm{OA}$ and fascial closure arms.

\section{Cost-effectiveness analysis alongside the trial in year 1}

Total quality-adjusted life years at the 1-year mark will be determined for each individual in the trial using mortality and QoL data. The incremental cost-effectiveness ratio (ICER) will be calculated as:

$$
\mathrm{ICER}=\frac{C_{\mathrm{OA}}-C_{\mathrm{PFC}}}{Q_{\mathrm{OA}}-Q_{\mathrm{PFC}}}
$$

where $C_{\mathrm{OA}}$ is the mean cost of the open abdomen strategy, $C_{\mathrm{PFC}}$ is the mean cost in the standard-of-care primary fascial closure strategy, $Q_{\mathrm{OA}}$ is the value of qualityadjusted life years (QALYs) associated with surgery with an open abdomen strategy, and $Q_{\mathrm{PFC}}$ is the value of QALYs associated with the primary fascial closure strategy.

The ICER will be expressed in 2020 CAD per QALY. A bootstrapping approach using sampling with replacement will be used to create an overall estimate of the ICER with confidence intervals based on 1000 samples from the study population.

\section{Modeling of cost-effectiveness beyond 1 year}

If neither the OA or fascial closure strategy is economically dominant (i.e., better outcomes but also higher costs accruing in one treatment arm), Markov modeling will be used to estimate cost, QALYs, and cost per QALY gained at the 2-, 5-, 10-year, and lifetime horizons.

To perform this analysis, a set of mutually exclusive, collectively exhaustive health states after surgery for SCIAS will be determined. These might include, for example, complete recovery, recovery with ileostomy or colostomy, chronic dependence on renal replacement therapy, neurologic impairment due to stroke or complications of critical illness, and death. The transition probabilities between these health states will be estimated using existing literature, COOL study data, and locally available datasets. A cycle length of 1 year will be used. Each health state will be assigned utility values. Across a simulated population of patients, total QALYs gained and additional costs accrued (from, for example, further surgery), as well as the cost per QALY, will be estimated. Future costs and benefits will be discounted at 1.5\% per annum.

Monte Carlo simulation will then be used to determine a cost-effectiveness acceptability curve.

\section{Sample size and power}

A limitation in conducting a cost-effectiveness analysis in the context of an RCT is that trials are powered to demonstrate differences in clinical outcome and not necessarily differences in cost between treatment arms. In this case, power will also be limited by costing resources within the population of patients recruited in Calgary, Canada-meaning less variability in costing estimates.

This limitation in power will be mitigated by using extensive sensitivity and scenario analyses including the above bootstrapping approach to define a cost effectiveness acceptability curve. 


\section{Compliance with reporting guidelines and methodological literature}

This analysis follows CADTH (Canadian Agency for Drugs and Technologies in Health) guidelines for the economic evaluation of health technologies [17]. The reference case we plan to use is a cost-utility analysis. The intervention and its standard-of-care comparator are clearly delineated, and the setting for the economic analysis has been established. We will use a publiclyfunded health care payer perspective over a lifetime horizon, with future discounting of costs and benefits at $1.5 \%$. Subgroups with potentially differing costs and benefits have been prespecified. We will include all relevant costs; effectiveness, including quality of life valuation, will be provided by the outcomes of the COOL trial. The results of this analysis will be reported following existing guidelines.

\section{Discussion}

The COOL trial is being conducted in centers around the world, giving rise to a diverse study population and clinically generalizable results. We plan to incorporate all available data on health resource use from global sites, and, combined with unit cost data from the Calgary microcosting environment, establish estimates of total cost for each treatment arm. This approach accounts for differing health resource use at all study sites while creating a single estimate of the ICER that can be used by clinicians and hospital leaders in evaluating the OA strategy. However, it does not account for how the economic context might differ between the countries and centers in which the trial is being conducted; unit costs of specific health resources may differ significantly. For resources that are found to be the main drivers of cost, we will therefore obtain unit costs from all sites and conduct extensive sensitivity analyses. Through these sensitivity analyses, we will create a more complete picture of the incremental cost-effectiveness ratio in individual sites where costs and even outcomes may differ.

\section{Conclusions}

To date, the cost of managing patients using an openabdomen ANPPT approach compared with managing patients using SCIAS remains unknown. The COOL trial has begun to recruit participants and full accrual is anticipated by December, 2023. If the trial demonstrates improved outcomes with an OA strategy, accurate estimation of the cost-effectiveness of this approach will be necessary prior to its widespread adoption. Our proposed analysis will address this critical question.

\section{Abbreviations}

ANPPT: Active negative pressure peritoneal therapy; CADTH: Canadian Agency for Drugs and Technologies in Health; COOL: Closed Or Open after Laparotomy; ICER: Incremental cost-effectiveness ratio; OA: Open abdomen;
QALY: Quality-adjusted life year; QOL: Quality of life; SCIAS: Severe complicated intra-abdominal sepsis

\section{Acknowledgements}

Not applicable

\section{Authors' contributions}

JNK, AK, and BM conceived the study. JNK drafted the manuscript. ERM provided insights into microcosting in Calgary and expertise in the conduct of cost-effectiveness analyses. SL provided data and insight into the operating room costing methodology in Calgary. JM provided methodological expertise on the conduct of the COOL trial. All authors critically reviewed the manuscript and approve of its content.

\section{Funding}

The Acelity Corporation (San Antonio, Texas) provided unrestricted funding for an Investigators Planning Meeting in Parma, Italy, on November 26, 2017, and provided an unrestricted funding grant to complete this study. The Acelity Corporation had no input into the design of the study and has no control of the analysis, interpretation, or dissemination of the trial data and results, all of which remain under the sole control of the Academic Independent Investigators.

The Departments of Critical Care Medicine and Surgery at the University of Calgary will provide unrestricted academic funding to support the conduct of the randomized trial. The analysis, interpretation, or dissemination of the trial data and results of these investigations will remain under the sole control of the Academic Independent Investigators including the Department of Critical Care Medicine at the University of Calgary.

\section{Availability of data and materials}

Not applicable

\section{Ethics approval and consent to participate}

The $\mathrm{COOL}$ trial is currently approved by the Conjoint Research Ethics Board of the University of Calgary (REB-16-1588) to proceed with a delayed consent process given the time-sensitive critical nature of decision-making. Research ethics will vary throughout the world and it is anticipated that various local policies concerning community consent, waiver of consent, or informed consent of significant patient proxies will vary among the local approaches to ensure that the COOL trial is performed to the highest ethical standards on a global basis.

\section{Consent for publication}

Not applicable

\section{Competing interests}

The authors declare that they have no competing interests.

\section{Author details}

${ }^{1}$ Department of Critical Care Medicine, University of Calgary, 2500 University Drive NW, Calgary, Alberta T2N 1 N4, Canada. ${ }^{2}$ Department of Medicine, Section of Infectious Diseases, University of Calgary, Calgary, Canada. ${ }^{3}$ Department of Surgery, University of Calgary, Calgary, Canada. ${ }^{4}$ Surgical Services, Alberta Health Services, Calgary, Canada. ${ }^{5}$ Department of Medicine, University of Calgary, Calgary, Canada. ${ }^{6}$ Department of Community Health Sciences, University of Calgary, Calgary, Canada. ${ }^{7} T$ The Trauma Program, University of Calgary, Calgary, Canada.

Received: 16 January 2020 Accepted: 7 February 2020

Published online: 21 February 2020

\section{References}

1. Moore LJ, Moore FA, Todd SR, Jones SL, Turner KL, Bass BL. Sepsis in general surgery: the 2005-2007 national surgical quality improvement program perspective. Arch Surg. 2010;145(7):695-700

2. Szakmany T, Lundin RM, Sharif B, et al. Sepsis prevalence and outcome on the general wards and emergency departments in Wales: results of a multicentre, observational, point prevalence study. PLoS One. 2016;11(12): e0167230. 
3. Sartelli M, Catena F, Ansaloni L, et al. Complicated intra-abdominal infections worldwide: the definitive data of the CIAOW study. World $J$ Emerg Surg. 2014;9:37.

4. Opmeer BC, Boer KR, van Ruler O, et al. Costs of relaparotomy on-demand versus planned relaparotomy in patients with severe peritonitis: an economic evaluation within a randomized controlled trial. Crit Care. 2010; 14(3):R97.

5. Kriwanek S, Armbruster C, Dittrich K, Beckerhinn P, Schwarzmaier A, Redl E. Long-term outcome after open treatment of severe intra-abdominal infection and pancreatic necrosis. Arch Surg. 1998;133(2):140-4.

6. van Ruler $\mathrm{O}$, Mahler CW, Boer KR, et al. Comparison of on-demand vs planned relaparotomy strategy in patients with severe peritonitis: a randomized trial. JAMA. 2007;298(8):865-72.

7. Kirkpatrick AW, Coccolini F, Ansaloni L, et al. Closed Or Open after Source Control Laparotomy for severe complicated intra-abdominal sepsis (the COOL trial): study protocol for a randomized controlled trial. World J Emer Surg. 2018;13:26.

8. Emr B, Sadowsky D, Azhar N, et al. Removal of inflammatory ascites is associated with dynamic modification of local and systemic inflammation along with prevention of acute lung injury: in vivo and in silico studies. Shock. 2014;41(4):317-23.

9. Kubiak BD, Albert SP, Gatto LA, et al. Peritoneal negative pressure therapy prevents multiple organ injury in a chronic porcine sepsis and ischemia/ reperfusion model. Shock. 2010;34(5):525-34.

10. Coccolini F, Montori G, Ceresoli M, et al. The role of open abdomen in nontrauma patient: WSES consensus paper. World J Emerg Surg. 2017;12:39.

11. Coccolini F, Roberts D, Ansaloni L, et al. The open abdomen in trauma and non-trauma patients: WSES guidelines. World J Emerg Surg. 2018;13:7.

12. Frick KD. Microcosting quantity data collection methods. Med Care. 2009; 47(7 Suppl 1):S76-81.

13. Canadian Institute for Health Information. Standards for management information systems in Canadian Health Service Organizations. Ottawa: Canadian Institute for Health Information; 2019.

14. Sharma R, Abdulla I, Fairgrieve-Park L, Mahdavi S, Burkart B, Bakal J. Surgical approaches in total hip arthroplasty cost per case analysis: a retrospective, matched, micro-costing analysis in a socialised healthcare system. Hip Int. 2019:1120700019839039

15. Reardon PM, Fernando SM, Van Katwyk S, et al. Characteristics, outcomes, and cost patterns of high-cost patients in the intensive care unit. Crit Care Res Pract. 2018;2018:5452683.

16. Koopmanschap MA, Rutten FF, van Ineveld BM, van Roijen L. The friction cost method for measuring indirect costs of disease. J Health Econ. 1995; 14(2):171-89.

17. CADTH. Guidelines for the economic evaluation of health technologies: Canada. Ottawa; 2017.

\section{Publisher's Note}

Springer Nature remains neutral with regard to jurisdictional claims in published maps and institutional affiliations.

Ready to submit your research? Choose BMC and benefit from:

- fast, convenient online submission

- thorough peer review by experienced researchers in your field

- rapid publication on acceptance

- support for research data, including large and complex data types

- gold Open Access which fosters wider collaboration and increased citations

- maximum visibility for your research: over $100 \mathrm{M}$ website views per year

At $\mathrm{BMC}$, research is always in progress.

Learn more biomedcentral.com/submissions 